\title{
Model construction of soybean average diameter and hole parameters of seed-metering wheel based on DEM
}

\author{
Guoqiang Dun ${ }^{1 *}$, Ning Mao' ${ }^{1}$, Zhiyong Gao ${ }^{2}$, Xingpeng Wu' ${ }^{1}$, Wenhui Liu ${ }^{1}$, Cheng Zhou ${ }^{3}$ \\ (1. College of Mechanical and Electrical Engineering, Northeast Forestry University, Harbin 150040, China; \\ 2. School of Fundamental Physics and Mathematical Sciences, Hangzhou Institute for Advanced Study, UCAS, Hangzhou 310012, China; \\ 3. School of Information Engineering, Huzhou University, Huzhou 313000, Zhejiang, China)
}

\begin{abstract}
To satisfy the demands of soybean precision sowing, this article starts with statistics of the physical parameters of soybean seeds in Heilongjiang province, China. The filling process of soybean seeds was analyzed, and the ratio relationship between the diameter, depth, chamfer length of seed-metering wheel's holes and the mean diameter of soybean seeds was determined. EDEM was used to simulate seeding circumstances of hole seed-metering wheel with different holes' sizes. The hole diameter ratio, hole depth ratio, and chamfer length ratio were the test factors, while the percentage of single multiple and the empty seeds were test indexes. The triple quadratic regression orthogonal rotation combination test was designed, and the mathematical model between test indexes and test factors was established. Results showed that the influence of hole diameter ratio and hole depth ratio was significant $(p<0.01)$ in the case of single, multiple and empty seed percentage while chamfer length ratio was only significant in single seed percentage compared to multiple and empty seeds percentage $(p>0.05)$. The chamfer length ratio was 0.15 , the hole diameter ratio was $1.63-1.73$, the hole depth ratio was $0.81-1.20$, the quality of seeding index was more than 90 , and multiple and missing indexes were less than $6 \%$ and $4 \%$, respectively. The soybean hole wheel seeding device was produced under the optimal parameter combination, to perform a comparative verification test with non-optimized parameters. The test showed anastomotic simulation results, verified the validity of the simulation. The seeding device after optimization expressed the best operating performance, which might satisfy the demands of soybean precision sowing. The study results can provide a theoretical reference for the optimization design of soybean seeding devices. Keywords: agricultural machinery, soybean, seed-metering device, hole seed-metering wheel, EDEM simulation, optimization DOI: $10.25165 /$ j.ijabe.20221501.5914
\end{abstract}

Citation: Dun G Q, Mao N, Gao Z Y, Wu X P, Liu W H, Zhou C. Model construction of soybean average diameter and hole parameters of seed-metering wheel based on DEM. Int J Agric \& Biol Eng, 2022; 15(1): 101-110.

\section{Introduction}

Soybean is one of the major foodstuffs in China, which is of irreplaceable importance in China's foodstuff demand, and is widely favored by Chinese consumers because of its high nutritional value $e^{[1,2]}$. From the current situation of foodstuff market demand and foodstuff yield, soybean planting is a key link of agricultural development in China, and the development and improvement of soybean planting technology, especially seeding technology, has an important impact on increasing soybean yield.

Northeast China is the main producing area of soybean, and the quality of the seed metering device plays a decisive role in the sowing effect ${ }^{[3]}$. Currently, there are two main types of seed metering devices on the market, which are mechanical ${ }^{[4-6]}$ and air-suction ${ }^{[7]}$. Air-suction seeding device can effectively solve the problem of repeat and missed sowing caused by uneven seed size, but it requires high manufacturing accuracy, high power consumption,

Received data: 2020-05-22 Accepted data: 2021-10-30

Biographies: Ning Mao, Undergraduate, research interest: agricultural engineering and information technology, Email: 76174408@qq.com; Zhiyong Gao, Undergraduate, research interest: mechanical design, Email: gaogzy99@163.com; Xingpeng Wu, Undergraduate student, research interest: agricultural engineering and information technology, Email: 1052795452@ qq.com; Wenhui Liu, Undergraduate student, research interest: mechanical engineering, Email: 1095269772@qq.com; Cheng Zhou, PhD, research interest: agricultural engineering, Email: 343404187@qq.com.

*Corresponding author: Guoqiang Dun, PhD, Lecturer, research interest: agricultural equipment and machinery. Northeast Forestry University, College of Mechanical and Electrical Engineering, Harbin 150040, China. Tel: +86-13836027042, Email: dunguoqiang1986@163.com. external power source, and so on. At present, the research on the precise soybean sowing in China mainly focuses on whether the soybean seeds can be filled into the holes of the seed-metering wheel accurately. If the holes are too big, lots of seeds can be filled into holes, which results in over sowing. If the holes are too small, the seeds cannot be filled into the holes, resulting in missing sowing. Liu et al. ${ }^{[8]}$ aimed at the problem that when the working speed of the mechanical seeding device increased, the seed filling index decreased too fast, and designed a tilting plate soybean seeding device to satisfy the need for a high-speed operation. However, in the process of discharging seeds, it is necessary that carry out classification screening of seeds' size, and the labor intensity is large and the work is complicated. Jia et al. ${ }^{[9]}$ designed an air-suction mechanical compound soybean seeding device in view of the technical problem that a large number of seed metering devices are prone to leakage when negative pressure plummets, which further improved the performance of high-speed precise seed metering devices. Zhang ${ }^{[10]}$ used mechanical thrust at the bottom of the seed row hole to overcome the problem of hole blockage for the cell wheel seeding device. Liu et al. ${ }^{[11]}$ designed a horizontal disc seed device with a chamfer circumferential inclined rectangular hole by analyzing the parameters of seed devices' type holes, which could adapt to different varieties of corn seeds. Dun et al. ${ }^{[12]}$ used linear regression model, grain weight physical model and quadratic regression model to predict the mean diameter of soybean seeds respectively, and based on this, built a combined prediction model of soybean seed mean diameter. The results showed that the physical model with the highest prediction accuracy was grain weight, and it was feasible to predict the mean 
diameter of soybean seeds by relying on grain weight. Based on the research of the world, the function model between the diameter, depth and chamfer length of the seeding device and the geometric parameters of different varieties of soybean has not been established. Therefore, the establishment of the mathematical model of soybean seed sizes and hole parameters and the optimization of the hole parameters are of great significance to realize the precise sowing of the mechanical seeders.

Current research analyzed the physical parameters of the soybean seeds in Heilongjiang province, China, and conducted a theoretical analysis with the filling process of soybean seeds, and the hole seed-metering wheel is seen as the research object, with the design of three factors five levels quadratic orthogonal rotating test, the 3D model of seeding device is established to do discrete element simulation experiment, and combining the response surface method to optimize the best parameters of holes, then based on the parameters to make hole seed-metering wheel, which is one part of soybean hole wheel seeding device ${ }^{[13]}$ then with the bench comparison verification test, to verify the optimization of the parameters. Hoping that can provide a reference for the optimization of soybean hole wheel seeding device structure parameters, and achieving the precise seeding.

\section{Analysis on hole seed-metering wheel}

\subsection{Physical parameters of soybean seeds}

100 seeds for each of four kinds of soybeans (Kendou-40, Kenfeng-17, Heidadou, Heihe-44) commonly used in Northeast China were selected as experimental materials for measurement. An Airuize-1332 digital vernier caliper (200 mm range, $0.01 \mathrm{~mm}$ accuracy) was used to measure the triaxial dimensions of soybean, namely seed length $a$, seed width $b$, and seed thickness $c$, as shown in Figure 1.

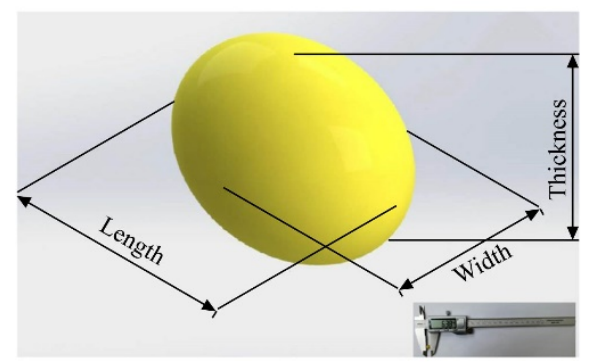

Figure 1 The triaxial dimensions of soybean

The mean diameter $d$ of soybean seeds was calculated according to Equation (1). The volume $V$ of soybean was calculated according to Equation (2) for the volume of the unequal ellipsoid. Huachaco UTP-313 electronic analytical balance (500 $\mathrm{g}$ range, $0.001 \mathrm{~g}$ accuracy) was used to measure the soybean seed mass $m$ and 100 -seed weight. The mean density $\rho$ of soybean was calculated according to Equation (3).

$$
\begin{gathered}
d=\sqrt[3]{a \cdot b \cdot c} \\
V=\frac{4}{3} \pi\left(\frac{a}{2} \cdot \frac{b}{2} \cdot \frac{c}{2}\right)=\frac{1}{6} \pi a b c \\
\rho=\frac{m}{V}
\end{gathered}
$$

where, $d$ is the mean diameter of soybean seeds, $\mathrm{mm} ; a$ is the length of a single soybean seed, $\mathrm{mm} ; b$ is the width of a single soybean seed, $\mathrm{mm}$; $c$ is the thickness of a single soybean seed, $\mathrm{mm}$; $V$ is the volume of single soybean seed, $\mathrm{mm}^{3} ; m$ is the mass of single soybean seed, $\mathrm{g} ; \rho$ is the density of single soybean seed,

\begin{tabular}{|c|c|c|c|c|c|}
\hline \multirow{2}{*}{ Indexes } & \multirow{2}{*}{ Value } & \multicolumn{4}{|c|}{ Soybean varieties } \\
\hline & & Kendou-40 & Kenfeng-17 & Heidadou & Heihe-44 \\
\hline \multirow{2}{*}{ Length/mm } & Average & 6.28 & 6.87 & 8.34 & 6.70 \\
\hline & Std. & 0.29 & 0.39 & 0.55 & 0.41 \\
\hline \multirow{2}{*}{ Width/mm } & Average & 6.35 & 6.73 & 7.75 & 6.10 \\
\hline & Std. & 0.28 & 0.28 & 0.40 & 0.30 \\
\hline \multirow{2}{*}{ Thickness/mm } & Average & 5.74 & 6.38 & 6.52 & 5.13 \\
\hline & Std. & 0.31 & 0.30 & 0.50 & 0.29 \\
\hline \multirow{2}{*}{$\begin{array}{c}\text { Average } \\
\text { diameter/mm }\end{array}$} & Average & 6.12 & 6.66 & 7.50 & 5.94 \\
\hline & Std. & 0.29 & 0.32 & 0.48 & 0.33 \\
\hline \multirow{2}{*}{$\begin{array}{l}\text { Single seed } \\
\text { quality/g }\end{array}$} & Average & 0.14 & 0.19 & 0.26 & 0.14 \\
\hline & Std. & 0.03 & 0.03 & 0.05 & 0.02 \\
\hline \multirow{2}{*}{$\begin{array}{c}\text { Single seed } \\
\text { volume } / \mathrm{mm}^{3}\end{array}$} & Average & 119.85 & 154.45 & 220.66 & 109.78 \\
\hline & C.V. & 0.12 & 0.13 & 0.15 & 0.12 \\
\hline \multirow{2}{*}{$\begin{array}{c}\text { Single seed } \\
\text { density } / \mathrm{g} \cdot \mathrm{mm}^{-3}\end{array}$} & Average & 0.0012 & 0.0012 & 0.0012 & 0.0013 \\
\hline & C.V. & 0.10 & 0.11 & 0.13 & 0.11 \\
\hline $\begin{array}{c}\text { A hundred seeds' } \\
\text { weight/g }\end{array}$ & -- & 14.35 & 19.27 & 26.49 & 20.88 \\
\hline
\end{tabular}
$\mathrm{g} / \mathrm{mm}^{3}$. The measurement results are listed in Table 1 .
Table 1 Measurement results of size of soybean seeds

\subsection{Introduction to soybean hole wheel seeding device}

The soybean hole wheel seeding device is also called a vertical disc seeder, which is a mechanical seeder. It has the characteristics of simple structure, low processing cost and reliable performance ${ }^{[14]}$. The soybean hole wheel seeding device is widely used in precision seeders in China.

As shown in Figure 2, the soybean hole wheel seeding device is composed of a seedbox, a disturbance roller, a seed-clearing brush, a seed-clearing knife and a hole seed-metering wheel. When the soybean hole wheel seeding device is working, it is divided into three stages: seed-filling, seed-clearing and seed-metering. Holes are evenly distributed on the circumference of the hole seed-metering wheel. When the seed-metering wheel rotates counterclockwise, the seeds in the seedbox enter the holes under gravity, friction and the pressure of other seeds, and move with the seed-metering wheel to complete the seed-filling process. Due to the larger diameter of the hole than the diameter of the seed, and unfixed seed size, etc., there are multiple seeds or no seeds in some holes. In order to remove excess seeds, a seed-clearing brush was designed. Before the seed enters the seed-metering area, the seed-clearing brush sweeps away the excess seeds in the nest hole, reducing the shearing and squeezing force that the seed directly enters the seed-metering area, thereby reducing the rate of seed damage. Because the seed has a large internal friction coefficient, during seed metering, the seed located above the tow layer is stationary and easily forms an overhead state, which greatly reduces the probability that the seed enters the hole. In order to eliminate this disadvantage and reduce the percentage of empty seeds, a disturbance roller is designed. It can eliminate overhead, direct seeds to the holes, and increase the working velocity of the seed-metering device.

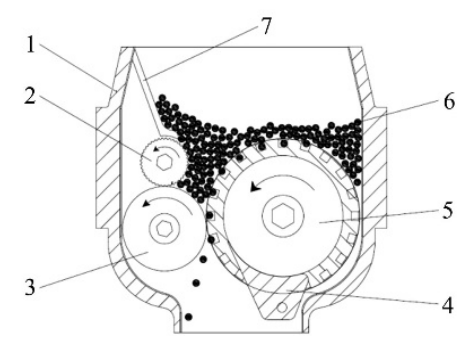

1. Seed box 2. Disturbance roller 3. Seed-clearing brush 4. Seed-clearing knife 5. Hole seed-metering wheel $\quad 6$. Soybean seeds 7. Retaining seeds disc Figure 2 Structure diagram of soybean hole wheel seeding device 


\subsection{Hole diameter ratio}

During seed filling, the hole seed-metering wheel and seeds are always in a moving state. Whether the seeds can be filled into the hole depends on the relative movement of the seed and the surface of the hole ${ }^{[15,16]}$. In order to facilitate theoretical analysis and ignore the influence of seed interactions and resistances, taking single seed as the research objects, the hole seed-metering wheel rotates counterclockwise. The relative movement between the seed and the hole seed-metering wheel is shown in Figure 3.

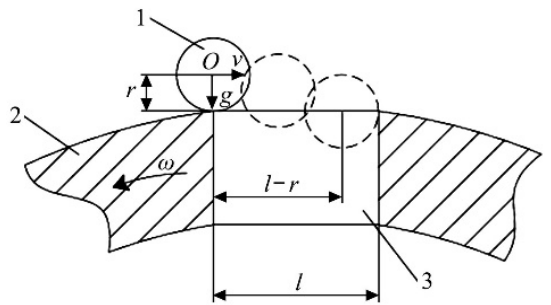

1. Soybean seed 2. Hole seed-metering wheel 3. Hole

Note: $r$ is the radius of seed, $\mathrm{mm} ; O$ is the centroid of soybean seed; $g$ is the acceleration of gravity, $\mathrm{m} / \mathrm{s}^{2} ; \omega$ is the rotation speed, $\mathrm{r} / \mathrm{min} ; v$ is the relative velocity of the seed and the hole, $\mathrm{m} / \mathrm{s} ; l$ is the diameter of hole, $\mathrm{mm}$.

Figure 3 Relative movement of seed and seed-metering wheel

Taking a seed as the research object, the centroid of the seed has the following motions, as shown in Equations (4)-(6):

In the horizontal direction:

$$
l-r=v t
$$

In the vertical direction:

$$
r=\frac{1}{2} g t^{2}
$$

Eliminating time $(t)$, we get the maximum relative velocity of seed filling hole:

$$
v=(l-r) \sqrt{\frac{g}{2 r}}
$$

where, $l$ is the diameter of the hole, mm; $r$ is the radius of the seed, $\mathrm{mm} ; v$ is the relative velocity of the seed and the hole, $\mathrm{m} / \mathrm{s} ; g$ is the acceleration of gravity, $\mathrm{m} / \mathrm{s}^{2} ; t$ is the minimum time for the seed to be filled into the hole, $\mathrm{s}$.

Since soybean seeds are unequal spheroids, the relationship between the diameter of the hole and the mean diameter of the seed was analyzed in two ways seeds are filled into the hole horizontally and by turning $90^{\circ}$.

\subsubsection{Seed being filled into the hole horizontally}

It can be seen from Table 1 that the triaxial dimensions of soybean seeds are different. Therefore, the seeds will have six different attitudes in the cross-section of the hole seed-metering wheel before they are filled into the holes, that is, at the edge of the holes. The movement of the seed being filled into the hole horizontally is shown in Figure 4.

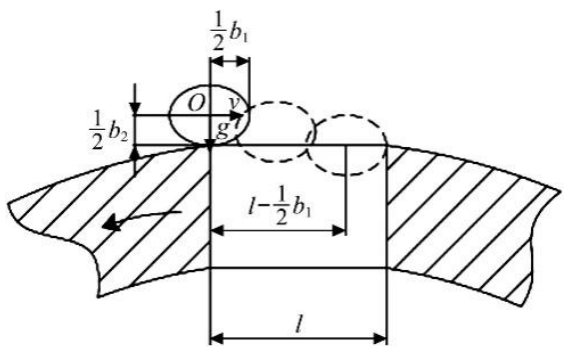

Note: $b_{1}, b_{2}$ are the section width and height of soybean seed respectively, $\mathrm{mm}$.

Figure 4 Seed fills into hole horizontally

When a soybean seed is horizontally moved, the seed centroid has the following movements, as shown in Equations (7) and (8):
In the horizontal direction:

$$
l-\frac{1}{2} b_{1}=v t
$$

In the vertical direction:

$$
\frac{1}{2} b_{2}=\frac{1}{2} g t^{2}
$$

where, $b_{1}$ is the section width of soybean seed, $\mathrm{mm} ; b_{2}$ is the section height of soybean seed, $\mathrm{mm}$.

Based on Equations (7) and (8), the ratio $k_{1}$ of the hole diameter $(l)$ to the mean seed diameter $(d)$ can be derived as:

$$
k_{1}=\frac{l}{d}=\frac{\frac{1}{2} b_{1}+v \sqrt{\frac{b_{2}}{g}}}{d}
$$

where, $k_{1}$ is the ratio of the diameter of the hole to the mean diameter of the seed when the hole is filled horizontally with the seed, which is simplified to hole diameter ratio later.

When the seed-metering device works, if the relative velocity (v) of the seed and the hole is too high, the velocity of the disturbance layer near the hole seed-metering wheel is too high, the seed will be hard to be filled into the hole, which will lead to decrease in the filling rate. If the relative velocity $(v)$ is too low, seed-metering efficiency will become slower. According to related research, the relative velocity $(v)$ of seed and hole is preferably $0.3 \mathrm{~m} / \mathrm{s}$. According to the specific dimension parameters of soybean seeds in Table 1, the six states in Figure 5
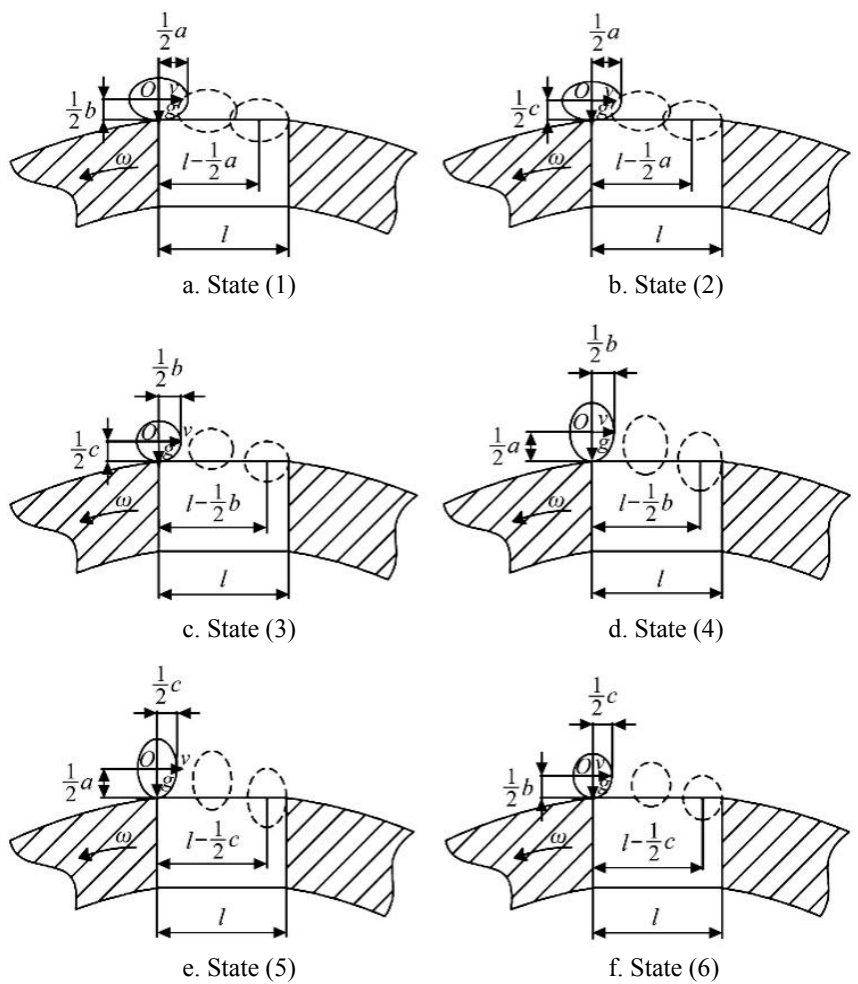

Note: $a$ is the length of a single seed, $\mathrm{mm} ; b$ is the width of a single seed, $\mathrm{mm} ; c$ is the thickness of a single seed, mm; State (1) indicates that the seed is filled into the hole horizontally taking $a$ as the section width and $b$ as the section height; State (2) indicates that the seed is filled into the hole horizontally taking $a$ as the cross section width and $c$ as the cross section height; State (3) means that the seed is filled into the hole horizontally taking $b$ as the cross section width and $c$ as the cross section height; State (4) means the seed is filled into the hole horizontally taking $b$ as the cross section width and $a$ as the cross section height; State (5) indicates that the seed is filled into the hole horizontally taking $c$ as the cross section width and $a$ as the cross section height; State (6) indicates that the seed is filled into the hole horizontally taking $c$ as the cross section width and $b$ as the cross section height.

Figure 5 States analysis of seed fills into hole horizontal 
and the section correspondence, the triaxial dimensions, the relative velocity $(v)$ and mean diameter $(d)$ of soybean seeds are sequentially brought into Equation (9), the hole diameter ratio $\left(k_{1}\right)$ in 6 states can be calculated. The specific hole diameter ratio is shown in Table 2. When the seed is filled into the hole horizontally, the value of the hole diameter ratio ranges from 1.55 to 1.83 .

Table 2 Hole diameter ratio of seed horizontal movement

\begin{tabular}{cccccc}
\hline \multirow{2}{*}{ State } & \multirow{2}{*}{ Index } & \multicolumn{4}{c}{ Varieties } \\
\cline { 3 - 6 } & & Kendou-40 & Kenfeng-17 & Heidadou & Heihe-44 \\
\hline$(1)$ & 1.76 & 1.70 & 1.68 & 1.82 \\
$(2)$ & 1.70 & 1.67 & 1.59 & 1.72 \\
$(3)$ & Hole & 1.71 & 1.65 & 1.55 & 1.67 \\
$(4)$ & diameter & 1.76 & 1.70 & 1.68 & 1.83 \\
$(5)$ & ratio & 1.71 & 1.67 & 1.60 & 1.75 \\
$(6)$ & & 1.72 & 1.66 & 1.56 & 1.69 \\
\hline
\end{tabular}

2.3.2 Seed being filled into the hole horizontally by turning $90^{\circ}$

Figure 6 shows the movement of the soybean seed being filled into the hole by turning $90^{\circ}$.

When a soybean seed is turned $90^{\circ}$, the seed centroid has the following movements, as shown in Equations (10)-(11):

In the horizontal direction:

$$
l-\frac{1}{2} b_{2}=v t
$$

In the vertical direction:

$$
\begin{gathered}
\frac{1}{2} b_{2}=\frac{1}{2} g t^{2} \\
k_{1}^{\prime}=\frac{l}{d}=\frac{\frac{1}{2} b_{2}+v \sqrt{\frac{b_{2}}{g}}}{d}
\end{gathered}
$$

where, $k_{1}{ }^{\prime}$ is the hole diameter ratio when the seed is filled into the hole by turning $90^{\circ}$. Based on Equations (10)-(11), eliminating time $(t)$, it is possible to deduce the ratio $\left(k_{1}{ }^{\prime}\right)$ of the hole diameter $(l)$ of seed-metering wheel to the mean diameter $(d)$ of the seed.

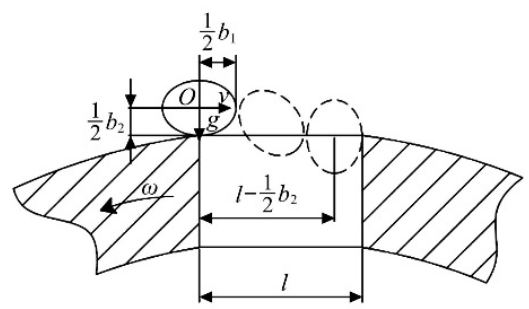

Figure 6 Seed fills into hole by turn $90^{\circ}$

It can be known from Equation (12) that when a soybean seed is filled into the hole by turning $90^{\circ}$, the hole diameter ratio is only related to the section height of the seed and has nothing to do with the section width. Therefore, when researching the seed being filled into hole by turning $90^{\circ}$, it is only necessary to take into account the three states of seed length, seed width, and seed thickness as the seed section height, as shown in Figure 7.
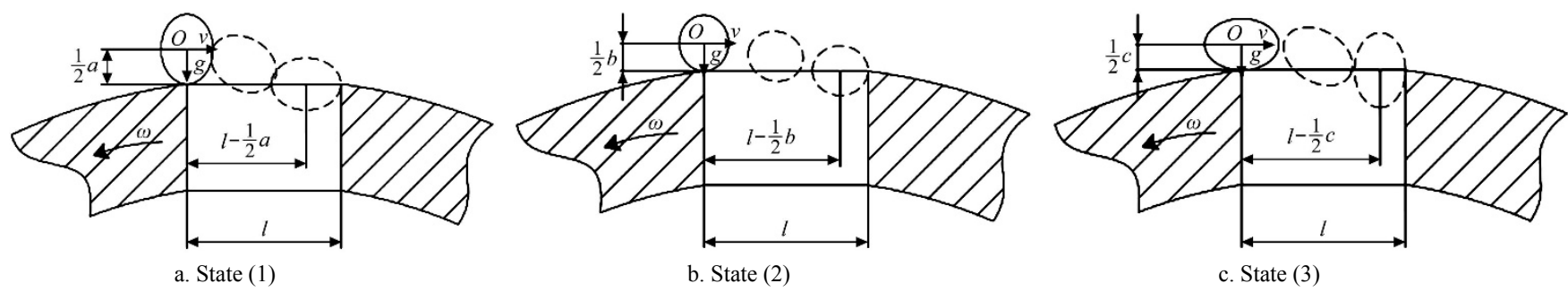

Figure 7 States analysis of seed fills into hole by turn $90^{\circ}$

According to Equation (12) and Table 1, the hole diameter ratio $\left(k_{1}{ }^{\prime}\right)$ in the three states can be calculated. As shown in Table 3 , when a seed is filled into the hold by turning $90^{\circ}$, the hole diameter ratio ranges from 1.47 to 1.88 . Considering the range of horizontal seed filling from 1.55 to 1.83 , it is finally determined that the range of hole diameter ratio is 1.47 to 1.88 .

Table 3 Type hole diameter ratio of seed turn movement

\begin{tabular}{lccccc}
\hline & & \multicolumn{4}{c}{ Varieties } \\
\cline { 3 - 6 } States & Index & Kendou-40 & Kenfeng-17 & Heidadou & Heihe-44 \\
\cline { 3 - 6 } & & 1.75 & 1.71 & 1.72 & 1.88 \\
$(1)$ & Hole diameter & 1.77 & 1.69 & 1.64 & 1.77 \\
$(2)$ & ratio & 1.66 & 1.63 & 1.47 & 1.59 \\
\hline
\end{tabular}

\subsection{Hole depth ratio}

According to the introduction to the seed-metering wheel in Chapter 2.2, for the depth of the hole, in the seed-filling area, it should be ensured that the seeds can be smoothly filled into the holes and stay in the holes stably. In the seed-clearing area, it should be ensured that a single seed remains in the hole and excess seeds are separated from the hole. In the seed-metering area, it should be ensured that the holes can smoothly discharge the seeds, and even other components can be used to force them to discharge.

As shown in Figure 8, define the hole depth as $d^{\prime}$, and get the ratio of the hole depth of seed-metering wheel to the average diameter of soybean seed according to Equation (13):

$$
k_{2}=\frac{d^{\prime}}{d}
$$

where, $k_{2}$ is the ratio of the hole depth of seed-metering wheel to the average diameter of soybean seed, which is simplified to hole depth ratio later.

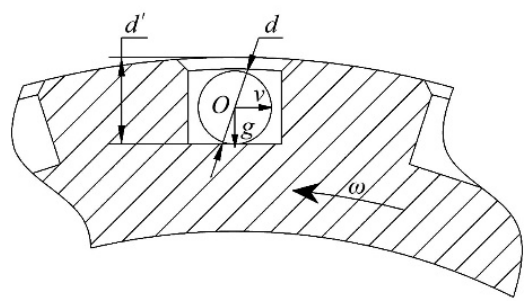

Figure 8 Analysis of hole depth

Based on the theoretical and practical requirements, referring to the relevant research ${ }^{[17]}$, it is concluded that the range of hole depth ratio is as follows:

$$
0.75 \leq k_{2} \leq 1.25
$$

\subsection{Chamfer length ratio}

In the actual working process of the soybean hole seeding device, the hole seed-metering wheel rotates in one direction. Therefore, the soybean nest hole seed-metering wheel is cut chamfer only in the forward direction, and not cut chamfer in the other direction, which is beneficial to the filling of soybean seeds and prevents the soybean seeds from slipping. 
As shown in Figure 9, a seed is at the edge of the hole seed-metering wheel, the centroid is at point $O$, and the radius of the seed is $r$. The cases with and without chamfer were studied respectively.

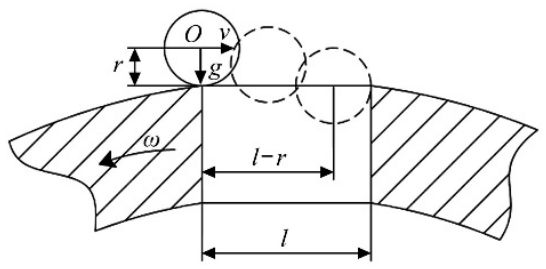

a. Hole without chamfer

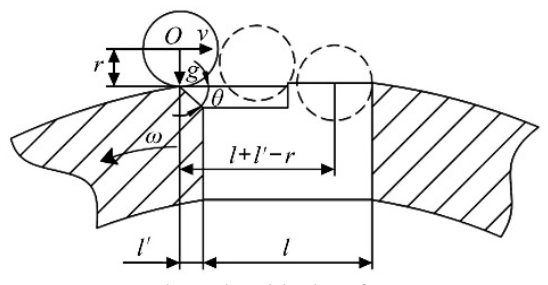

b. Hole with chamfer

Note: $r$ is the radius of seed, $\mathrm{mm} ; O$ is the seed centroid; $\theta$ is the degree of chamfer, $\left(^{\circ}\right) ; l$ is the length of hole, $\mathrm{mm} ; l^{\prime}$ is the length of chamfer, $\mathrm{mm}$.

Figure 9 Analysis of hole chamfer

In the process of filling a single soybean seed into the hole, the velocity $(v)$ of the seed relative to the hole seed-metering wheel plays a major role. If velocity $(v)$ is too low, the seed-metering frequency is too low, which will lead to inefficient seed metering. If velocity $(v)$ is too high, the seeds are too late to be filled into the holes, which will cause missed seed metering. Therefore, in order to make the soybean hole seeding device have good seed-metering performance, it is necessary to study the maximum velocity $\left(v_{\max }\right)$ at which the seeds can pass through the holes.

The equation of seed motion without chamfer is

$$
\left\{\begin{array}{l}
l-r=v t \\
r=\frac{1}{2} g t^{2}
\end{array}\right.
$$

where, $r$ is the height of the seed centroid above the seeding plate (the radius of seed), $\mathrm{mm}$.

Obtained after transformation:

$$
v=(l-r) \sqrt{\frac{g}{2 r}}
$$

When there is a chamfer $(\theta)$ in the hole seed-metering wheel, the movement of soybean seed is as follows:

$$
\left\{\begin{array}{l}
l+l^{\prime}-r=v t \\
r=\frac{1}{2} g t^{2}
\end{array}\right.
$$

where, $l^{\prime}$ is the length of chamfer, $\mathrm{mm}$.

Obtained after transformation:

$$
v^{\prime}=\left(l+l^{\prime}-r\right) \sqrt{\frac{g}{2 r}}
$$

The ratio of the chamfer length of the hole to the mean diameter is,

$$
k_{3}=\frac{l^{\prime}}{d}
$$

where, $k_{3}$ is the ratio of the chamfer length of the hole seed-metering wheel to the mean diameter of soybean seeds, which is simplified to chamfer length ratio later.

According to Equation (16) and Equation (18), chamfer can increase relative velocity by $\Delta v=l^{\prime} \sqrt{\frac{g}{2 r}}$. The hole can fill the single seed more accurately and reduce the seed breaking rate. The maximum velocity of soybean seeds relative to the seed-metering hole is related to the length of the chamfer and the centroid position of soybean. When the chamfer length is too large, the seed may collide with the chamfer during falling, which will affect the seed falling into the hole. If the chamfer length is too short, it cannot play its role. It is determined that the chamfer length ratio is $0-0.3$.

\section{Simulation experiment based on EDEM}

In the process of discharging seeds, soybean hole wheel seeding device was accompanied with a mass of seeds' movement, in the process of perturbation of seeds, entering into the cell feed wheel, and cleaning, there is certainly accompanied with gravity, friction, pressure and so on ${ }^{[18-20]}$. As a kind of efficient way to analyze the movement of particles DEM has been applied in industry and agriculture ${ }^{[21,22]}$. It's mentioned that the analysis about soybean and soybean hole wheel seeding device, and here, the establishment of soybean particle model and the EDEM simulation experiment will be introduced.

\subsection{Confirming of seeds model and contact parameters}

To simulate the movement situation of soybean in soybean hole seeding device accurately, this essay applies the ellipse ideal particle models ${ }^{[23]}$. The Kenfeng-17 that can represent northeastern soybean seeds' size is chosen as the experimental type (seed length is $6.87 \mathrm{~mm}$, seed width is $6.73 \mathrm{~mm}$, seed thickness is $6.38 \mathrm{~mm}$ the average diameter is $6.66 \mathrm{~mm}$ ), the particle model is set as Figure 10.

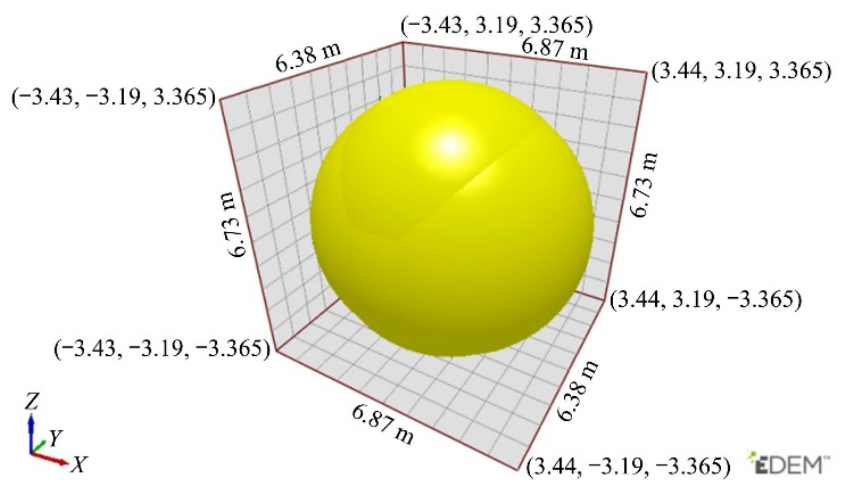

Figure 10 Soybean particle model in EDEM

Table 4 Variable parameter in EDEM

\begin{tabular}{clc}
\hline \multicolumn{1}{c}{ Item } & \multicolumn{1}{c}{ Variable } & Value \\
\hline \multirow{2}{*}{ Soybean seeds } & Poisson's ratio & 0.23 \\
& Shear modules $/ \mathrm{Pa}$ & $6.04 \times 10^{6}$ \\
& Solid density $/ \mathrm{kg} \cdot \mathrm{m}^{-3}$ & 1290 \\
\hline \multirow{2}{*}{ Seed box and Hole } & Poisson's ratio & 0.43 \\
seed-metering wheel & Shear modules $/ \mathrm{Pa}$ & $1.3 \times 10^{9}$ \\
& Solid density $/ \mathrm{kg} \cdot \mathrm{m}^{-3}$ & 1240 \\
\hline \multirow{2}{*}{ Seed-clearing brush } & Poisson's ratio & 0.40 \\
& Shear modules $/ \mathrm{Pa}$ & $1.0 \times 10^{8}$ \\
& Solid density $/ \mathrm{kg} \cdot \mathrm{m}^{-3}$ & 1150 \\
\hline \multirow{2}{*}{ Seeds to seeds } & Coefficient of restitution & 0.30 \\
& Coefficient of static friction & 0.39 \\
& Coefficient of rolling friction & 0.17 \\
\hline \multirow{2}{*}{ Seeds to seed box and } & Coefficient of restitution & 0.52 \\
hole seed-metering wheel & Coefficient of static friction & 0.15 \\
& Coefficient of rolling friction & 0.09 \\
\hline \multirow{2}{*}{ Seeds to seed-clearing } & Coefficient of restitution & 0.45 \\
brush & Coefficient of static friction & 0.50 \\
& Coefficient of rolling friction & 0.01 \\
\hline
\end{tabular}


The surface of soybean seed is slippy and has no adhesive power, and the Hertz-Mindlin (no-slip) model is selected as simulation contact model ${ }^{[24,25]}$, and the other parameters such as seed particle properties, seed box properties, seed-clearing brush wheel properties and their interaction properties ${ }^{[26]}$, which are set as Table 4.

\subsection{Establishment and import of geometric model}

Design and establish the 3D model of seeding apparatus with Solidworks 2012, get rid of the unnecessary and non-contacting structures and save as .step file. Import the .step file to EDEM, and set the parameters of model parts according to Table 4 . Set the rotate speed for hole seed-metering wheel, at the same time, set Particle Factory on soybean hole seeding device. The total number of particles is 300 , and the target number (per second) is 3000, and the simulation model is shown in Figure 11.
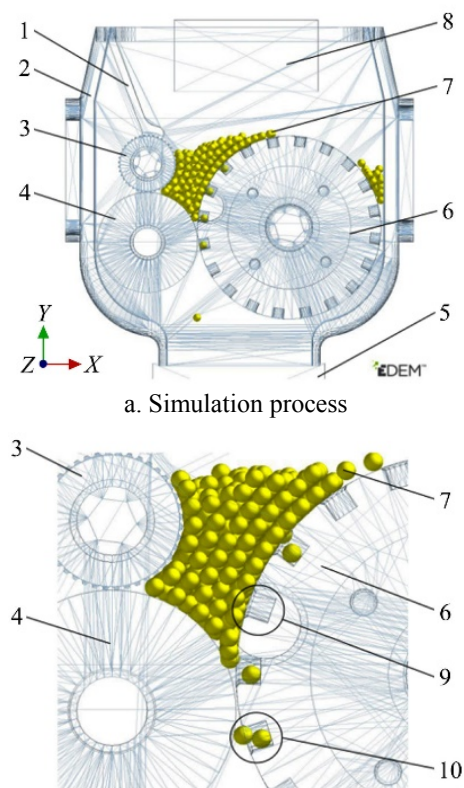

b. Multiple and missing seeds in EDEM

1. Retaining seeds disc 2. Seed box 3. Disturbance roller 4. Seed-clearing brush 5. Seed collection chassis 6. Hole seed-metering wheel 7. Soybean seeds 8 . Particle factory 9. Phenomenon of missing seeds 10. Phenomenon of multiple seeds

Figure 11 Simulation model and simulation process

\subsection{Simulating calculation}

According to the practical application, the operating speed of the actor machine is $0.6 \mathrm{~m} / \mathrm{s}$, the theoretical distance of seeds is 5 centimeters, the diameter of hole seed-metering wheel is $130 \mathrm{~mm}$, and the circumferential uniform 20 holes on hole seed-metering wheel. It is calculated that the rotation speed of the hole seeding-metering wheel is $36 \mathrm{r} / \mathrm{min}$. The wheel and the seeding-clearing brush are driven by gear engagement, and the transmission ratio is $1.0-1.2$, then the rotation speed of seed-clearing brush is $43 \mathrm{r} / \mathrm{min}$.

In the process of simulation, the time step needs to be confirmed to trace the friction and collision between particles to calculate the energy consumption of the particle system. Time step is the time lag between two calculations, and the stationary time steps can ensure the continuity of simulation work ${ }^{[27]}$. Usually, the time step applies to Rayleigh time step:

$$
T_{R}=\pi R \frac{\sqrt{\frac{\rho}{G}}}{0.163 v+0.8766}
$$

where, $R$ is the radius of particle, $\mathrm{mm}$; $\rho$ is the density of particle $\mathrm{kg} / \mathrm{m}^{3} ; G$ is the shear elasticity, $\mathrm{Pa} ; v$ is Poisson's ratio.
In actual application, this rated time step is about $15 \%-20 \%$. $\pi=3.14, R=3.3 \mathrm{~mm}, \rho=1290 \mathrm{~kg} / \mathrm{m}^{3}, G=6.04 \times 10^{6} \mathrm{~Pa}, v=0.23$ are substituted into Equation (20), and $16.7 \%$ is obtained as the time step of the simulation. The shorter the save interval is, the more accurate the simulation will be, but the simulation time will also increase. In this simulation, $0.01 \mathrm{~s}$ is set as save interval. The fewer particles in each grid cell, the higher the efficiency of the simulator. For the simulation with little or no particle size change, the ideal value may be between $2 R_{\min }$ to $3 R_{\min }$. Here, $3 R_{\min }$ is set as cell size.

\section{Experimental design based on response surface}

Response Surface Methodology is a kind of statistical approach that applies a reasonable experimental design method, uses the quadratic equation of multiple variables to match the function relationship of fitting factors and response values, and finds optimal process parameters through the analysis of regression equation to solve the multivariate problems ${ }^{[28]}$.

\subsection{The selection of experimental factors}

From the introduction in 2.3-2.5, hole diameter ratio is $k_{1}$, hole depth ratio is $k_{2}$, chamfer length ratio is $k_{3}$, all of these are important parameters during the process of seed filling of soybean hole wheel seeding device. Therefore, hole diameter ratio, hole depth ratio, and chamfer length ratio are selected as three elements in the parameter optimization test.

\subsection{Confirming test index}

According to the requirement of soybean sowing, the percentage of single seed (\%), the percentage of multiple seeds (\%), and the percentage of empty seeds (\%) can be seen as an index of parameter optimization test in Equations (21)-(23), during the process of sowing, it is required that the percentage of single seed is high, and the percentage of multiple seeds and the percentage of empty seeds are low.

$$
\begin{aligned}
& y_{1}=\frac{n_{1}}{N} \times 100 \% \\
& y_{2}=\frac{n_{2}}{N} \times 100 \% \\
& y_{3}=\frac{n_{3}}{N} \times 100 \%
\end{aligned}
$$

where, $N$ is the total number of seeds in the experiment; $n_{1}$ is the number of holes that are filled with one seed; $n_{2}$ is the number of holes that are filled with multiple seeds; $n_{3}$ is the number of holes that are not filled.

\subsection{Method and result of the experiment}

Looking up related essays ${ }^{[29]}$, the experimental method for the design of quadrature rotating combination of ternary quadratic regression ${ }^{[30]}$ is applied, the regression model about the influence of factors on the index is established, and the experimental elements that affect the index are optimized. The experimental factors and levels code is in Table 5.

Table 5 Experimental factors and level codes

\begin{tabular}{cccc}
\hline Level & Hole diameter ratio $x_{1}$ & Hole depth ratio $x_{2}$ & Chamfer length ratio $x_{3}$ \\
\hline 1.682 & 1.88 & 1.25 & 0.30 \\
1 & 1.80 & 1.15 & 0.24 \\
0 & 1.68 & 1.00 & 0.15 \\
-1 & 1.55 & 0.85 & 0.06 \\
-1.682 & 1.47 & 0.75 & 0 \\
\hline
\end{tabular}

EDEM is used for simulation, each simulation test is repeated 3 times, and the average value is taken as the final test result. The experimental method and the results of EDEM simulation are shown in Table 6, and the results are done regression analysis with 
Design-Expert 8.0.6, then the change rules of index that under the influence of experimental factors are analyzed.

Table 6 Experimental project and results

\begin{tabular}{|c|c|c|c|c|c|c|}
\hline \multirow[b]{2}{*}{ No. } & \multicolumn{3}{|c|}{ Experimental factors } & \multicolumn{3}{|c|}{ Evaluation indexes } \\
\hline & $\begin{array}{c}\text { Hole } \\
\text { diameter } \\
\text { ratio } x_{1}\end{array}$ & $\begin{array}{l}\text { Hole depth } \\
\text { ratio } x_{2}\end{array}$ & $\begin{array}{c}\text { Chamfer } \\
\text { length ratio } \\
x_{3}\end{array}$ & $\begin{array}{l}\text { Percentage } \\
\text { of single } \\
\text { seed } / \%\end{array}$ & $\begin{array}{l}\text { Percentage } \\
\text { of multiple } \\
\text { seeds } / \%\end{array}$ & $\begin{array}{c}\text { Percentage } \\
\text { of empty } \\
\text { seeds } / \%\end{array}$ \\
\hline 1 & -1 & -1 & -1 & 88.23 & 3.12 & 8.65 \\
\hline 2 & 1 & -1 & -1 & 86.64 & 10.98 & 2.38 \\
\hline 3 & -1 & 1 & -1 & 90.81 & 3.43 & 5.76 \\
\hline 4 & 1 & 1 & -1 & 83.28 & 13.95 & 2.77 \\
\hline 5 & -1 & -1 & 1 & 88.75 & 2.43 & 8.82 \\
\hline 6 & 1 & -1 & 1 & 85.02 & 12.61 & 2.37 \\
\hline 7 & -1 & 1 & 1 & 90.12 & 3.02 & 6.86 \\
\hline 8 & 1 & 1 & 1 & 81.64 & 15.2 & 3.16 \\
\hline 9 & -1.682 & 0 & 0 & 88.94 & 1.62 & 9.44 \\
\hline 10 & 1.682 & 0 & 0 & 82.66 & 15.52 & 1.82 \\
\hline 11 & 0 & -1.682 & 0 & 90.75 & 2.43 & 6.82 \\
\hline 12 & 0 & 1.682 & 0 & 87.82 & 7.82 & 4.36 \\
\hline 13 & 0 & 0 & -1.682 & 88.79 & 5.4 & 5.81 \\
\hline 14 & 0 & 0 & 1.682 & 86.04 & 7.81 & 6.15 \\
\hline 15 & 0 & 0 & 0 & 90.77 & 5.45 & 3.78 \\
\hline 16 & 0 & 0 & 0 & 92.38 & 5.23 & 2.39 \\
\hline 17 & 0 & 0 & 0 & 92.62 & 3.4 & 3.98 \\
\hline 18 & 0 & 0 & 0 & 93.42 & 3.82 & 2.76 \\
\hline 19 & 0 & 0 & 0 & 92.03 & 4.55 & 3.42 \\
\hline 20 & 0 & 0 & 0 & 91.76 & 5.03 & 3.21 \\
\hline 21 & 0 & 0 & 0 & 92.02 & 4.35 & 3.63 \\
\hline 22 & 0 & 0 & 0 & 91.76 & 5.8 & 2.44 \\
\hline 23 & 0 & 0 & 0 & 91.59 & 5.18 & 3.23 \\
\hline
\end{tabular}

\section{Analysis of experimental results}

\subsection{Variance analysis of each evaluation index}

According to the data in Table 6, the result of variance analysis of each evaluation index from Design-Expert 8.0.6 is listed in Table 7. The relationships between three factors and three evaluation indexes from which are,

$$
\begin{aligned}
y_{1}= & 92.05-2.34 x_{1}-0.57 x_{2}-0.59 x_{3}-1.34 x_{1} x_{2}-0.39 x_{1} x_{3} \\
& -0.15 x_{2} x_{3}-2.29 x_{1}^{2}-1.06 x_{2}^{2}-1.72 x_{3}^{2} \\
y_{2}= & 4.73+4.69 x_{1}+1.14 x_{2}+0.43 x_{3}+0.58 x_{1} x_{2}+0.5 x_{1} x_{3} \\
& -0.012 x_{2} x_{3}+1.60 x_{1}^{2}+0.38 x_{2}^{2}+0.9 x_{3}^{2} \\
y_{3}= & 3.22-2.36 x_{1}-0.57 x_{2}+0.16 x_{3}+0.75 x_{1} x_{2}-0.11 x_{1} x_{3}+ \\
& 0.17 x_{2} x_{3}+0.69 x_{1}^{2}+0.68 x_{2}^{2}+0.82 x_{3}^{2}
\end{aligned}
$$

From the results of variance analysis in Table 7 , it can be known that the inspection results of the significance of each evaluation index regression model are all extremely significant, and the result of lack of fit is not significant. It indicates that the regression models' fitting degree in trial stretch is good. For the percentage of a single seed, the factors $x_{1}, x_{1} x_{2}, x_{1}{ }^{2}, x_{2}{ }^{2}, x_{3}{ }^{2}$ are extremely significant and the other factors are not significant. For the percentage of multiple seeds, the factors $x_{1}, x_{2}, x_{1}{ }^{2}, x_{3}{ }^{2}$ are

\begin{tabular}{|c|c|c|c|c|c|c|c|c|c|c|c|c|c|c|c|}
\hline \multirow{2}{*}{ Source } & \multicolumn{5}{|c|}{ Percentage of single seed } & \multicolumn{5}{|c|}{ Percentage of multiple seeds } & \multicolumn{5}{|c|}{ Percentage of empty seeds } \\
\hline & $\begin{array}{l}\text { Sum of } \\
\text { squares }\end{array}$ & df & $\begin{array}{l}\text { Mean } \\
\text { square }\end{array}$ & $F$-value & $p$-value & $\begin{array}{l}\text { Sum of } \\
\text { squares }\end{array}$ & $\mathrm{df}$ & $\begin{array}{l}\text { Mean } \\
\text { square }\end{array}$ & $F$-value & $p$-value & $\begin{array}{l}\text { Sum of } \\
\text { squares }\end{array}$ & df & $\begin{array}{l}\text { Mean } \\
\text { square }\end{array}$ & $F$-value & $p$-value \\
\hline$x_{1}$ & 74.47 & 1 & 74.47 & 112.92 & $<0.0001$ & 301.02 & 1 & 301.02 & 250.59 & $<0.0001$ & 76.04 & 1 & 76.04 & 197.43 & $<0.0001$ \\
\hline$x_{2}$ & 4.36 & 1 & 4.36 & 6.61 & 0.0232 & 17.65 & 1 & 17.65 & 14.69 & 0.0021 & 4.46 & 1 & 4.46 & 11.59 & 0.0047 \\
\hline$x_{3}$ & 4.75 & 1 & 4.75 & 7.20 & 0.0188 & 2.49 & 1 & 2.49 & 2.07 & 0.1735 & 0.36 & 1 & 0.36 & 0.94 & 0.3503 \\
\hline$x_{1} x_{2}$ & 14.28 & 1 & 14.28 & 21.66 & 0.0005 & 2.71 & 1 & 2.71 & 2.26 & 0.1567 & 4.55 & 1 & 4.55 & 11.8 & 0.0044 \\
\hline$x_{1} x_{3}$ & 1.19 & 1 & 1.19 & 1.81 & 0.2015 & 1.98 & 1 & 1.98 & 1.65 & 0.2216 & 0.099 & 1 & 0.099 & 0.26 & 0.6206 \\
\hline$x_{2} x_{3}$ & 0.19 & 1 & 0.19 & 0.29 & 0.6014 & 0.00125 & 1 & 0.00125 & 0.001041 & 0.9748 & 0.22 & 1 & 0.22 & 0.57 & 0.4621 \\
\hline$x_{1}^{2}$ & 83.44 & 1 & 83.44 & 126.51 & $<0.0001$ & 40.57 & 1 & 40.57 & 33.77 & $<0.0001$ & 7.65 & 1 & 7.65 & 19.85 & 0.0006 \\
\hline$x_{2}^{2}$ & 17.83 & 1 & 17.83 & 27.04 & 0.0002 & 2.29 & 1 & 2.29 & 1.91 & 0.1904 & 7.34 & 1 & 7.34 & 19.05 & 0.0008 \\
\hline$x_{3}^{2}$ & 47.04 & 1 & 47.04 & 71.32 & $<0.0001$ & 12.96 & 1 & 12.96 & 10.79 & 0.0059 & 10.62 & 1 & 10.62 & 27.56 & 0.0002 \\
\hline Lack of fit & 4.24 & 5 & 0.85 & 1.57 & 0.2718 & 10.64 & 5 & 2.13 & 3.42 & 0.0598 & 2.40 & 5 & 0.48 & 1.47 & 0.2976 \\
\hline Cor total & 254.36 & 22 & & & & 396.77 & 22 & & & & 115.99 & 22 & & & \\
\hline
\end{tabular}
extremely significant, and the other factors are not significant. For the percentage of empty seeds, the factors $x_{1}, x_{2}, x_{1} x_{2}, x_{1}^{2}, x_{2}^{2}$, $x_{3}{ }^{2}$ are extremely significant, and the other factors are not significant.

Table 7 Variance analysis of the influence of each factor on each evaluation index

Note: $p<0.01$ means extremely significant, $0.01<p<0.05$ means significant, $p>0.05$ means not significant. df: Degree of freedom.

\subsection{Response surface analysis of each evaluation index}

Design Expert 8.0.6 is used to obtain the response surface map of the influence of factors on evaluation indexes, which can clearly and intuitively see the relationships between factors and evaluation indexes.

Figure 12 shows the response surface of three factors to the percentage of a single seed. From this figure, it can be known that with the increase of numerical value of hole diameter ratio, hole depth ratio, and chamfer length ratio, the percentage of single seed always has the tendency of increase before decrease. From the actual working condition and the analysis to three factors, it is easy to know that when the diameter of holes is small, the soybean seed cannot fill in; and when the diameter of holes is big, multiple seeds can enter the holes, and causing the decline of the percentage of a single seed. Only by the diameter being at a middle situation, it can be ensured that there will be one seed drop down. When the depth of holes is shallow, the center of gravity of seeds are at the out of holes, and it is easy to be brushed away by seed-clearing brush; when the depth of holes is deep, there will be multiple seeds enter into the holes, so the percentage of single seed will decline. When the length of the chamfer is too short, chamfer doesn't work effectively; and when the length of chamfer is long, the cylindrical holes will change to conical holes, so the seeds are easily cleared in the process of seed-clearing, and the percentage of single seed can decline, too.

Figure 13 shows the response surface of three factors to the percentage of multiple seeds. From this figure, it can be known that the change of response surface changes obviously along the direction of holes diameter ratio, and with the increase of the ratio, the percentage of multiple seeds is in the tendency of increasing; the change of response surface changes slowly along with the holes depth ratio and the direction of chamfer length ratio. With the increase of value of hole depth ratio, the percentage of multiple 
seeds is in the tendency of increasing. With the increase of value of chamfer length ratio, the percentage of multiple seeds is in the tendency of decrease before the increase. From the actual working condition and the analysis of three factors, it is easy to know that when the diameter and depth of hole become bigger, more seeds drop into holes, which gives rise to the increase of the percentage of multiple seeds

Figure 14 shows the response surface of three factors to the

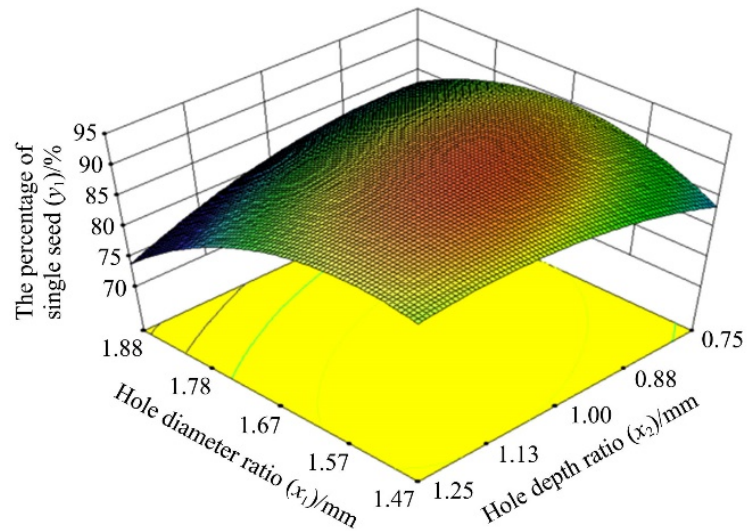

a. Response surface graph of hole diameter ratio $\left(x_{1}\right)$ and hole depth ratio $\left(x_{2}\right)$ to the percentage of single seed percentage of empty seeds. From this figure, the change of response surface along hole diameter ratio is obvious, and with the increase of the value of hole diameter rate, the percentage of empty seeds is in the tendency of decreasing; the change of response surface along with the whole depth ratio and chamfer length ratio is slow, and with the increase of hole depth ratio and chamfer length ratio, the percentage of empty seeds is in the tendency of decrease before the increase.

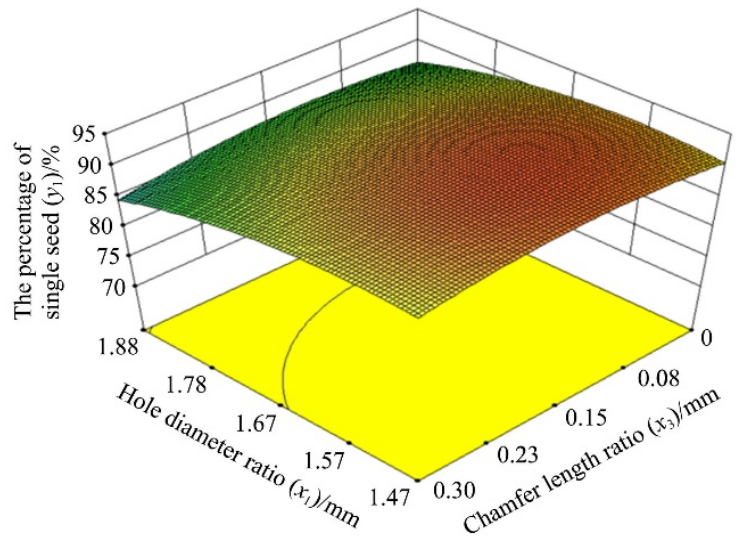

b. Response surface graph of hole diameter ratio $\left(x_{1}\right)$ and chamfer length ratio $\left(x_{3}\right)$ to the percentage of single seed

Figure 12 Response surface graph of three factors to the percentage of single seed

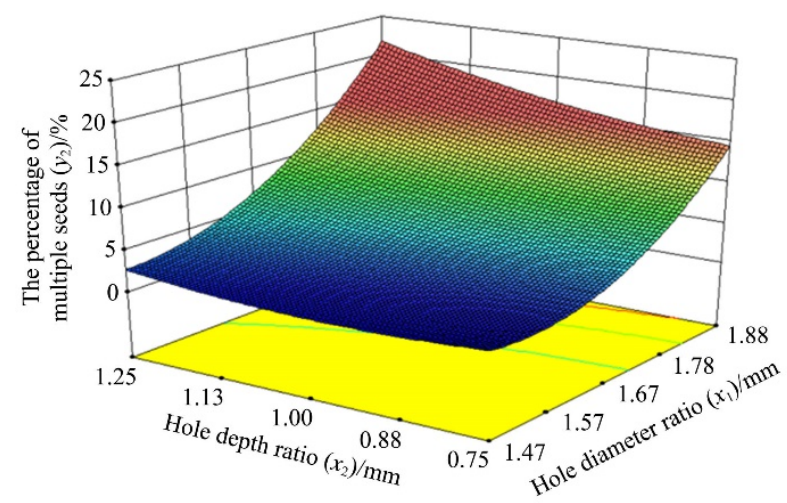

a. Response surface graph of hole diameter ratio $\left(x_{1}\right)$ and hole depth ratio $\left(x_{2}\right)$ to the percentage of multiple seeds

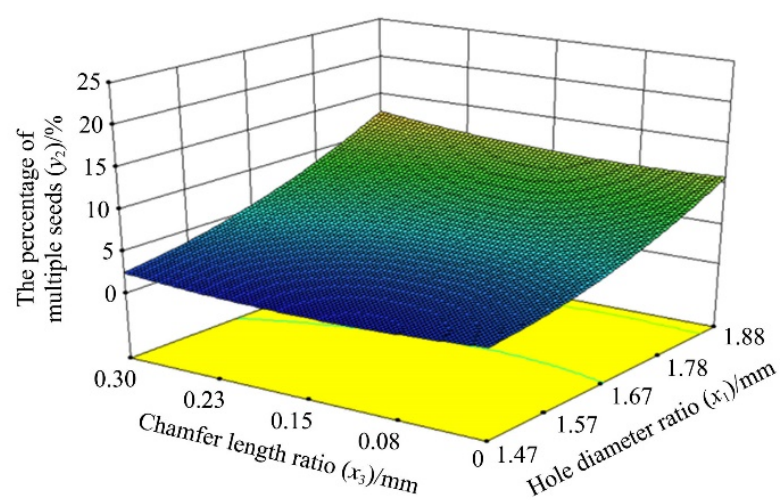

b. Response surface graph of hole diameter ratio $\left(x_{1}\right)$ and chamfer length ratio $\left(x_{3}\right)$ to the percentage of multiple seeds

Figure 13 Response surface graph of three factors to the percentage of multiple seeds

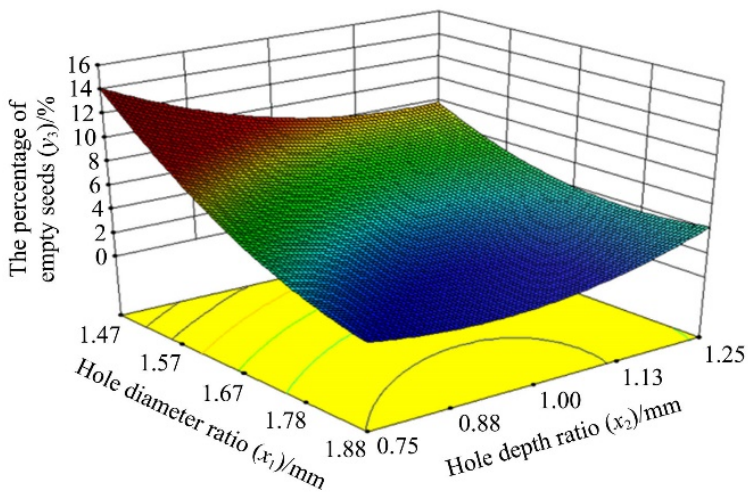

a. Response surface graph of hole diameter ratio $\left(x_{1}\right)$ and hole depth ratio $\left(x_{2}\right)$ to the percentage of empty seeds

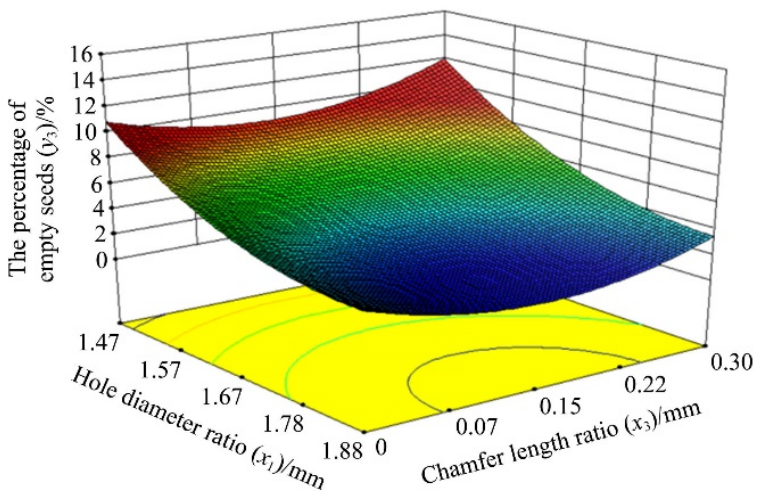

b. Response surface graph of hole diameter ratio $\left(x_{1}\right)$ and chamfer length ratio $\left(x_{3}\right)$ to the percentage of empty seeds

Figure 14 Response surface graph of three factors to the percentage of empty seeds

\subsection{Verification of best parameters}

Aiming at confirming proportional relation of hole parameters of seed-metering wheel and geometrical parameters of soybean, the parameters are optimally analyzed, and the experimental index is set as the percentage of single seed is greater than $90 \%$, the percentage of multiple seeds is less than $6 \%$, and the percentage of empty seeds is less than $5 \%$, and because of chamfer length ratio has less effect to experimental index, which is set as 0.15 , then do the parameters optimization. The best range of parameters is shown in Figure 15.

When the chamfer length ratio is 0.15 , the hole diameter ratio and hole depth ratio are at the optimum combination region, which 
is the yellow region in Figure 15. At this region, the hole diameter ratio is in the range of 1.63 to 1.73 , and hole depth ratio is in the range of 0.81 to 1.20 . The attainable percentage of a single seed is greater than $90 \%$, the percentage of multiple is less than $6 \%$, and the percentage of empty seeds is less than $4 \%$.

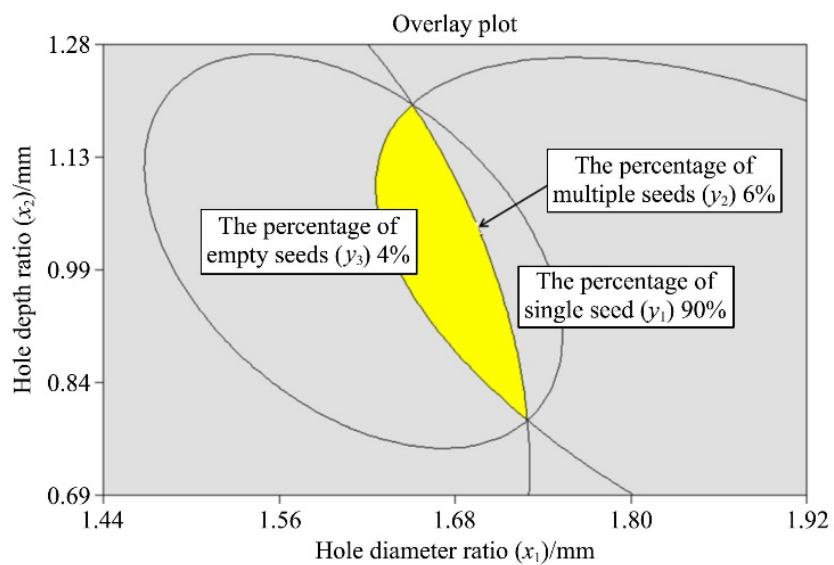

Note: Chamfer length ratio is 0.15 .

Figure 15 Figure of parameters optimization and analysis

To verify the feasibility of the simulation experiment and the validity of the optimized hole, the bench test is conducted. In order to avoid contingency in the simulation experiment, the KENDOU 44 soybean seeds (seed length is $6.28 \mathrm{~mm}$, seed width is $6.35 \mathrm{~mm}$, seed thickness is $5.74 \mathrm{~mm}$, and average diameter is $6.12 \mathrm{~mm}$ ) which are different from simulation experiment materials are selected as experimental materials. Using the soybean hole wheel seeding device as experimental seeding apparatus, and conducting a contrast test with the parameters in the gray region in Figure 15 and the hole seed-metering wheel with optimized parameters (in the yellow region in Figure 15), as listed in Table 8. The JPS-12 computer vision precision seed metering device performance test bench (produced by Heilongjiang province agricultural machinery research institute, China) is the experimental device.

Table 8 Hole size of seed-metering wheel in optimization group and contrast groups

\begin{tabular}{cccccccc}
\hline & $\begin{array}{c}\text { Hole } \\
\text { diameter } \\
\text { ratio }\end{array}$ & $\begin{array}{c}\text { Diameter } \\
\text { of hole } \\
/ \mathrm{mm}\end{array}$ & $\begin{array}{c}\text { Hole } \\
\text { depth } \\
\text { ratio }\end{array}$ & $\begin{array}{c}\text { Depth } \\
\text { of hole } \\
/ \mathrm{mm}\end{array}$ & $\begin{array}{c}\text { Chamfer } \\
\text { length } \\
\text { ratio }\end{array}$ & $\begin{array}{c}\text { Length of } \\
\text { chamfer } \\
/ \mathrm{mm}\end{array}$ \\
\hline $\begin{array}{c}\text { Optimization } \\
\text { group }\end{array}$ & 1 & 1.68 & 10.28 & 0.99 & 6.06 & 0.15 & 1.00 \\
\hline $\begin{array}{c}\text { Contrast } \\
\text { groups }\end{array}$ & 2 & 1.56 & 9.55 & 1.13 & 6.92 & 0.15 & 1.00 \\
\hline
\end{tabular}

The operating speed is set as $0.6 \mathrm{~m} / \mathrm{s}$, the plant distance is $5 \mathrm{~cm}$, and the quality of seeding index, multiples index, missing index are experimental indexes. In turn, three group experiments are conducted, and every group repeats three times to average. According to Test methods for single grain (precision) seeder (GB/T 6973-2005 in China) ${ }^{[31]}$ to conduct the experiment. It is conducted in the laboratory of The Engineering College of Northeast Agricultural University (Harbin, China) on November, 18th, 2019, as is shown in Figure 16.

The results of the experiment are shown in Table 9. Contrast the optimization groups and simulation results, they basically match, so the veracity of the optimization result is verified. After optimization, the hole seed-metering wheel has a high-quality seeding index and excellent performance of discharging seeds, so it can satisfy the requirement of precise sowing of soybean.

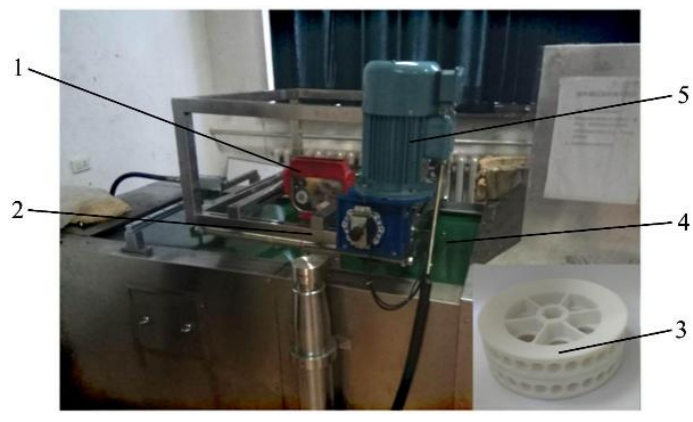

1. Soybean hole wheel seeding device 2. Mounting rack 3. Hole seed-metering wheels in contrast groups 4. Belt of seed bed 5. Motor

Figure 16 Graphic of bench test

Table 9 Results of bench test

\begin{tabular}{ccccc}
\hline Test group and group number & $\begin{array}{c}\text { Quality of seeding } \\
\text { index/\% }\end{array}$ & $\begin{array}{c}\text { Multiples } \\
\text { index/\% }\end{array}$ & $\begin{array}{c}\text { Missing } \\
\text { index/\% }\end{array}$ \\
\hline Optimization group & 1 & 91.6 & 5.8 & 2.6 \\
\hline Contrast groups & 2 & 87.2 & 4.8 & 8.0 \\
\hline
\end{tabular}

\section{Conclusions}

This study theoretically analyzes the filling process of soybean varieties in Heilongjiang province, China, and finds the ratio range of hole diameter to seeds average diameter is 1.47 to 1.88 , the ratio range of hole depth to seeds average diameter is 0.75 to 1.25 , and the ratio range of hole chamfer length to seeds average diameter is $0-0.3$.

Software EDEM was used to establish the discrete element simulation model of the soybean hole wheel seeding device. Through experiment design, the regression model between discharging performance index (the percentage of single seed, the percentage of multiple seeds, and the percentage of empty seeds) and the hole diameter ratio, the hole depth ratio, and the chamfer length ratio of the hole seed-metering wheel with soybean seeds, then do analysis and optimization with the method of the response surface, in the last, the best parameters are as follow: when the chamfer length ratio is 0.15 , the hole diameter ratio is in the range of 1.63-1.73, and the hole depth ratio is in the range of $0.81-1.20$, at this moment, the percentage of single seed is greater than $90 \%$, the percentage of multiple seeds is less than $6 \%$, and the percentage of empty seeds is less than $4 \%$.

According to the best parameters, the hole seed-metering wheel was designed, and the comparative verification experiment with two hole seed-metering wheels whose holes size are not in the range of optimization. The experimental results were basically matching with simulation result. The soybean hole wheel seeding device after optimization has a high-quality seeding index and excellent performance of discharging seeds, so it can satisfy the requirement of precise sowing of soybean.

\section{Acknowledgements}

This work was supported by the Fundamental Research Funds for the Central Universities, China (Grant No. 2572020BF03) and the Horizontal Project of Northeast Forestry University-Intelligent Plot Breeding Precision Sowing and Fertilization Equipment System (Grant No.43221026). The authors also acknowledge the anonymous reviewers for their critical comments and suggestions for improving the manuscript. 


\section{[References]}

[1] Yu N, Li L J, Schmitz N, Tian L F, Greenberg J A, Diers B W. Development of methods to improve soybean yield estimation and predict plant maturity with an unmanned aerial vehicle based platform. Remote Sensing of Environment, 2016; 187: 91-101.

[2] Cui G, Jiao Y P. China's soybean trade from the perspective of national food security. Journal of Social Sciences, 2019; 2: 13-28. (in Chinese)

[3] Zhang X G, Liu W, Yu Y C. Development status and trends of soybean precision seeding machinery in china. Soybean Science \& Technology, 2012; 2012(5): 39-42. (in Chinese)

[4] Wang J W, Tang H, Wang J F, Shen H G, Feng X, Huang H N. Analysis and experiment of guiding and dropping migratory mechanism on pickup finger precision seed metering device for corn. Transactions of the CSAM, 2017; 48(1): 29-37. (in Chinese)

[5] Yu J Q, Wang G, Xin N, Fu H. Simulation analysis of working process and performance of cell wheel metering device. Transactions of the CSAM, 2011; 42(12): 83-87. (in Chinese)

[6] Feng J, Zeng A J, Song W T, Liu Y J, Hu H L. Performance experiments of the seed-meter device with combined suckers. Transactions of the CSAE, 2007; 17(2): 84-87. (in Chinese)

[7] Yazgi A, Degi R Mencioglu A. Optimization of the seed spacing uniformity performance of a vacuum-type precision seeder using response surface methodology. Biosystems Engineering, 2007; 97(3): 347-356.

[8] Liu H X, Liu J X, Tang S F, Xu X M. Design on opposed inclined-plate high-speed precision seed-metering device and its working mechanism analysis. Transactions of the CSAE, 2016; 32(20): 24-31. (in Chinese)

[9] Jia H L, Chen Y L, Zhao J L, Wang J X, Guo M Z, Zhuang J. Design and experiment of pneumatic-mechanical combined precision metering device for soybean. Transactions of the CSAE, 2018; 49(4): 75-86, 139. (in Chinese)

[10] Zhang Y W. Research and design for making a new type of mechanized and multiple functions of precision seed-drilled appliance. Transactions of the CSAE, 2005; 2005(3): 51-53, 50. (in Chinese)

[11] Liu Y F, Lin J, Li B F, Song J P, Tian Y. Design and experiment of horizontal disc seed metering device for maize seeder. Transactions of the CSAE, 2017; 33(8): 37-46. (in Chinese)

[12] Dun G Q, Chen H T, Yang J L, Li R X, Dong B Z, Ming X L. Combined forecasting model of soybean seed average diameter based on the shapley value. Soybean Science, 2014; 33(6): 910-914. (in Chinese)

[13] Zhao R Y, Dai F, Zhao W Y, Shi L R, Guo X H, Li T H. Simulation test for nest-eye-wheel precision metering device with high fill rate based on discrete element method. Journal of Gansu Agricultural University, 2017; 52(1): 132-138. (in Chinese)

[14] Cui Y H, Jin H Y. A new type of seed pusher of precision seed metering mechanism with socket wheel. Journal of agronomy of Yanbian University, 2010; 32(2): 147-149. (in Chinese)

[15] Liu C L, Wang Y L, Du X, Song J N, Wang J C, Zhang F Y. Filling performance analysis and verification of cell-belt rice precision seed-metering based on friction and repeated filling principle. Transactions of the CSAE, 2019; 35(4): 29-36. (in Chinese)

[16] Gao H W, Zang Y. Experimental study on the cell of the horizontal plate precision meter for corn seed. Transactions of the CSAE, 2003; 19(2): 109-113. (in Chinese)

[17] Yang Z D, Yang S D, Zhang G H, Li H W. A seed metering device of variable hole depth. Journal of Agricultural Mechanization Research, 2010; 32(12): 103-105, 120. (in Chinese)

[18] Mao K M, Michale Y W, Xu Z W. DEM simulation of particle damping. Powder Technology, 2004; 142(2-3): 154-165.

[19] MISHRA B K, Murty C V R. On the determination of contact parameters for realistic DEM simulation of ball mills. Powder Technology, 2001; 115(3): 290-297.

[20] Zhu H P, Yu A B. A theoretical analysis of the force models in discrete element method. Powder Technology, 2005; 161(2): 122-129.

[21] Lu Z, Lü X L, Yan W M. A survey of particle damping technology. Journal of Vibration and Shock, 2013; 32(7): 1-7. (in Chinese)

[22] Xu S, Zhu F, Zhang J. An overview of the discrete element method and its coupling algorithms. Journal of Mechanics in Engineering, 2013; 35(1): 8-14.

[23] Guo L F. Optimization design and experiment study on hole of vertical disc soybean seed-metering device. Master dissertation. Harbin: Northeast Agricultural University, 2014; 100p. (in Chinese)

[24] Xu T Y, Yu J Q, Yu Y J. A modeling and verification approach for soybean seed particles using the discrete element method. Advanced Powder Technology, 2018; 29(12): 3274-3290.

[25] Wang J W, Tang H, Wang Q, Zhou W Q, Yang W P, Shen H G. Numerical Simulation and experiment on seeding performance of pickup finger precision seed-metering device based on EDEM. Transactions of the CSAE, 2015; 31(21): 43-50. (in Chinese)

[26] Zhang T, Liu F, Zhao M Q, Liu Y Q, Li F L, Ma Q, et al. Measurement of physical parameters of contact between soybean seed and seed metering device and discrete element simulation calibration. Journal of China Agricultural University, 2017; 22(9): 86-92. (in Chinese)

[27] Wang G Q, Hao W J, Wang J X. Discrete element method and practice on EDEM. Xi'an: Northwest Polytechnic University Press, 2010; 155p.

[28] Adalarasan R, Santhanakumar M, Rajmohan M. Application of Grey Taguchi-based response surface methodology (GT-RSM) for optimizing the plasma arc cutting parameters of $304 \mathrm{~L}$ stain less steel. The International Journal of Advanced Manufacturing Technology, 2015; 78(5-8): 266-275.

[29] Zhou Y, Hu M J, Xia J F, Zhang G Z, Xu Z Y, Feng C C, et al. Design and experiment of inside-filling adjustable precision seed-metering device with combined hole for cotton. Transactions of the CSAE, 2018; 34(18): 59-67. (in Chinese)

[30] Xu Z R. Regression analysis and experimental design. Beijing: China Agriculture Press, 1998; 179p.

[31] GB/T 6973-2005. Test method of single grain (precision) seeder. National Technical Committee for Agricultural Machinery Standardization. (in Chinese) 